\title{
Influence of seismic parameters on the performance of underground
}

\section{structures}

\author{
lu Qingrui ${ }^{1, a}$, Wang Zengliang ${ }^{1, b}$, Gao jinhe ${ }^{1, c}$ Chang $Y i^{1, d}$ \\ ${ }^{1}$ east china university of technology,school of civil and architecture engineering,nan chang,china \\ aqingrui_lu@ecit.cn, b1538419208@qq.com, cjhgao@ecit.cn, dyi_chang@ecit.cn
}

Key words: seismic damage, ground motion parameters, underground structures

Abstract:To study the seismic response of underground structures, it is of great value to investigate their performance induced by seismic events. This paper reviews the correlation of ground motion parameters and seismic damage of underground structures, so that the influence of such seismic factors as the peak ground acceleration, peak ground velocity, earthquake magnitude, duration and frequency on the seismic damage of underground structures can be well explained.

\section{Introduction}

Historically, underground facilities have experienced a lower rate of damage than surface structures. Nevertheless, some underground structures have experienced significant damage in recent large earthquakes, including the 1976 Tangshan, China earthquake, the 1995 Kobe, Japan earthquake, the 1999 Chi-Chi, Taiwan earthquake, and the 1999 Kocaeli, Turkey earthquake, and some more recent earthquakes such as the 2004 Niigata, Japan earthquake, and the 2008 Wenchuan, China earthquake. Especially, the Daikai subway station collapse as the first collapse of an urban underground structure due to earthquake forces, rather than ground instability (Youssef M.A. Hashash, 2001), significantly changes our belief that underground structures had the ability to sustain earthquakes with little damage.

Information on the performance of underground openings during earthquakes is relatively scarce, compared with that on the performance of surface structures. Despite the small proportion of the reported cases of damaged understructures during earthquakes, some efforts have been devoted to the investigations of damage performances. In the following part, the correlation between seismic parameters such as peak ground acceleration, peak ground velocity and earthquake magnitude is investigated, so that the damage mechanism of underground structures can be further illustrated.

\section{Peak ground acceleration}

In earthquake engineering, according to H.Dowding \& Rozen (1978), PGA is one of the most widely accepted index of the ground shaking intensity and damage. Ground motions with high peak accelerations are usually, although not always, more destructive than motions with lower peak accelerations (Kramer,1996). 
Table 1 The correlation of damage degree and peak ground acceleration (ALA, 2001)

\begin{tabular}{cccccc}
\hline PGA $(\mathrm{g})$ & All Tunnels & DS $=1$ & DS=2 & DS=3 & DS=4 \\
0.07 & 30 & 30 & 0 & 0 & 0 \\
0.14 & 19 & 18 & 1 & 0 & 0 \\
0.25 & 22 & 19 & 2 & 0 & 1 \\
0.37 & 15 & 14 & 0 & 0 & 1 \\
0.45 & 44 & 36 & 6 & 2 & 0 \\
0.57 & 66 & 44 & 12 & 9 & 1 \\
0.67 & 19 & 3 & 7 & 8 & 1 \\
0.73 & 2 & 0 & 0 & 2 & 0 \\
Total & 217 & 164 & 28 & 21 & 4 \\
\hline
\end{tabular}

Damage cases of tunnel structures documented by H.Dowding \& Rozen (1978), as shown in Figure 1 which was revised by Göran Bäckblom (2002), suggest that no damage should be expected if the peak surface accelerations are less than about $0.2 \mathrm{~g}$, and only minor damage will be experienced between 0.2 and $0.4 \mathrm{~g}$. According to the extended database of Owen\& Scholl(1981), little damage would be expected for rock tunnels for peak ground accelerations below $0.4 \mathrm{~g}$, as can be indicated from Figure 2. Sharma \& Judd (1991) further updated the previous database and concluded that no damage or minor damage occurred for PGA less than $0.15 \mathrm{~g}$, which can be shown by Figure 3.

Focusing on the damage induced by earthquake shaking other than by ground failure or fault movement, Power et al(1998) removed the relatively poorly documented cases as well as those caused directly by the other two seismic effects, and simultaneously added some recent cases, and then concluded that ground shaking caused less damage for PGA less than $0.2 \mathrm{~g}$, some cases damaged ranging from slight to moderate damage with PGA between $0.2 \mathrm{~g}$ and $0.5 \mathrm{~g}$, and some other cases suffered slight to heavy damage when PGA exceeded $0.5 \mathrm{~g}$, as shown in Figure2. Besides, the case of 1923 Kanto earthquake with PGA equal to $0.2 \mathrm{~g}$ suffered heavy damage probably due to landsliding other than ground shaking.

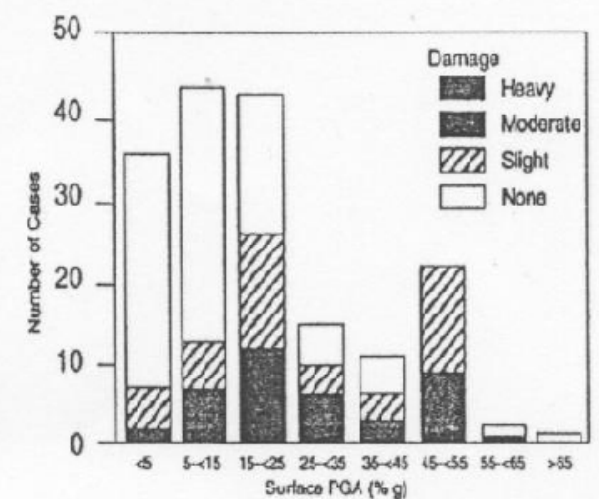

Figure 1 Effects of PGA on damage(Sharma \& Judd ,1991)

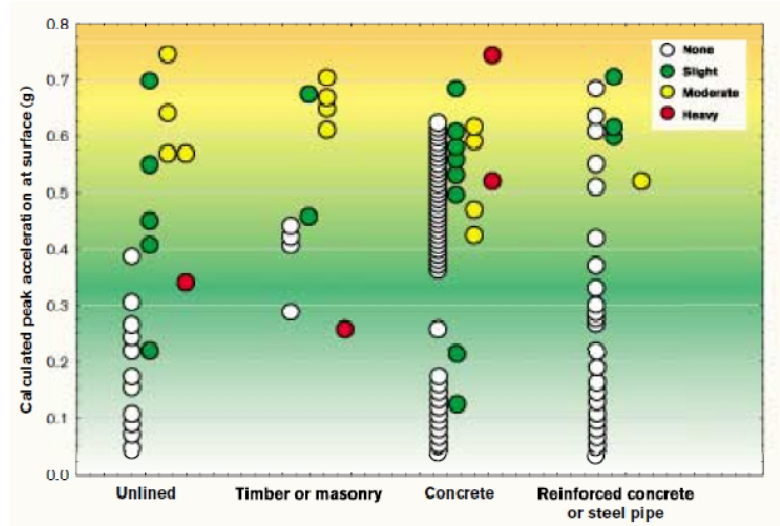

Figure 2 PGA and associated damage with different rock type(revision after Power, 1998 by Göran Bäckblom, 2002) 


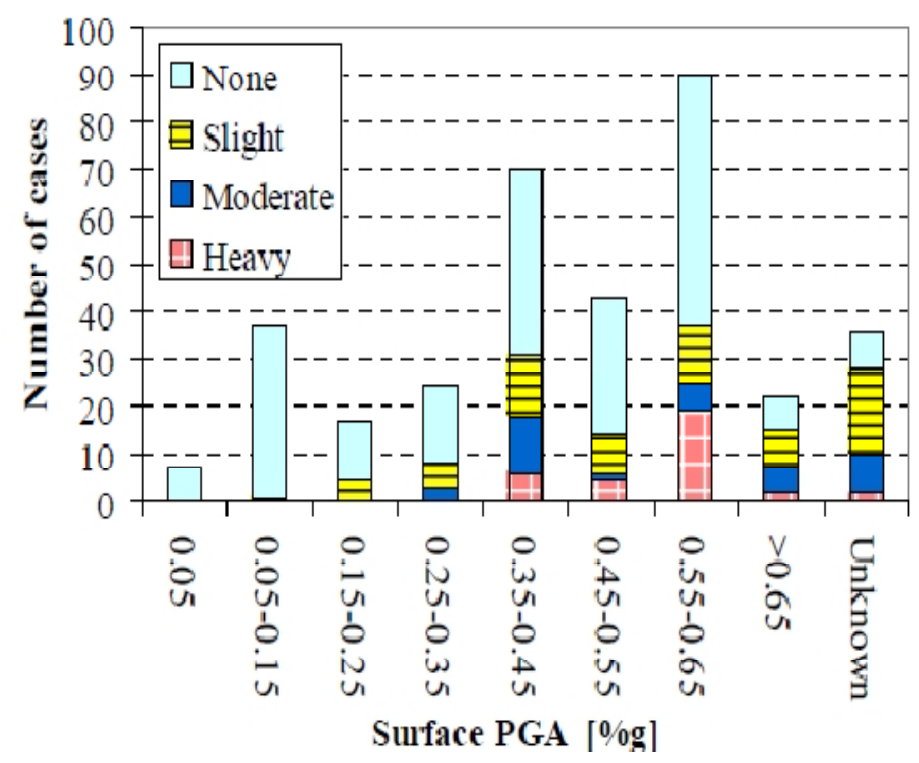

Figure 3 Effects of PGA on damage (Corigliano, 2007)

ALA(2001) studied 217 bored tunnels which suffered strong ground motions and obtained the correlation of damage degree and peak ground acceleration, as shown in Table 1, and it can be concluded that the general tendency is almost correspondent to previous conclusions. More recently, Corigliano(2007) updated the data derived from the post earthquake surveys after Chi-chi(Taiwan) and 2004 Niigata (Japan) earthquakes based on the database developed by Power et al(1998), and by his investigation, the influence of PGA on damage did not show a clearly increasing trend, which might be induced by the uncertainty involved in the calculation of PGA using empirical attenuation relations. However, it can be inferred from Figure 3 that almost no damage occurred for PGA less than $0.15 \mathrm{~g}$, the threshold of PGA leading to moderate damage was $0.25 \mathrm{~g}$, while heavy damage occurred when PGA exceeded $0.35 \mathrm{~g}$.

It can be concluded from above that damage could be related to peak ground acceleration to some extent, which was confirmed byDowding \& Rozen (1978) by pointing out that the use of acceleration as an index of acceleration could result in a workable method for determining the imminence of gross levels of damage.

\section{Peak ground velocity}

According to Corigliano(2007), velocity-time histories could better capture the intense, impulsive character of near-fault records than PGA, and the response of underground structures is governed by the imposed strain field, which may be correlated to the Peak Ground Velocity (PGV) through the following relationship:

$\mathrm{PGS}=\mathrm{PGV} / \mathrm{Ca}$

Besides, the peak particle velocity resulting from an earthquake of a given magnitude can be predicted to fall within reasonable narrow limits, compared with peak ground acceleration(C.M.St John\& T.F.Zahrah, 1987). Carpenter \& Chung(1986) also concluded that there existed closer relationship between peak velocity-damage than between peak acceleration and damage. Thus the intensity of ground motion shaking for assessing seismic damage of underground structures is better quantified in terms of PGV at the free surface(Corigliano, 2007). 
Dowding \& Rozen (1978) concluded from relevant investigations that minor damage would occur with peak ground velocity ranging between $20 \mathrm{~cm} / \mathrm{s}$ and $40 \mathrm{~cm} / \mathrm{s}$. The study of Owen \&Scholl(1981) suggested that the thresholds of minor damage and heavy damage are respectively $20 \mathrm{~cm} / \mathrm{s}$ and $90 \mathrm{~cm} / \mathrm{s}$, as shown in Figure 4.Based on the relation for predicting PGV developed by Bray\&Rodriguez-Marek(2004),Corigliano (2007) correlated PGV and the damage level, as shown in Figure 5, and showed that the moderate damage occurs with the PGV value ranging between 40 and $115 \mathrm{~cm} / \mathrm{s}$, which are higher than the values concluded by Owen \& Scholl(1981) and Dowding \& Rozen (1978). The correlation between PGV and case numbers for moderate damage level is shown in Figure 6.

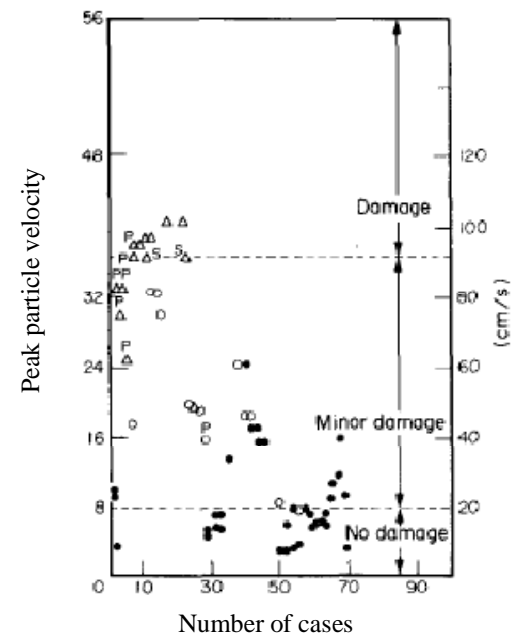

Figure 4 Calculated PPV and associated damage(Owen \& Scholl, 1981)

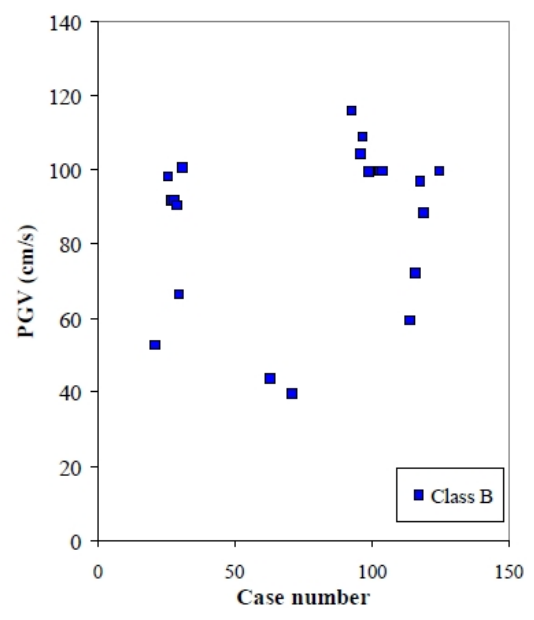

Figure 5 Correlation between PGV and damage class B (Corigliano, 2007)

The reliability of the correlation between damage and PGV still needs to be further analyzed and verified due to that PGV is usually evaluated at the free surface and it is often estimated using attenuation laws which carry a certain level of uncertainty. However, the relation between PGVand damage can be used for preliminary assessment of stability of underground structures before performing more refined analysis (Corigliano, 2007).

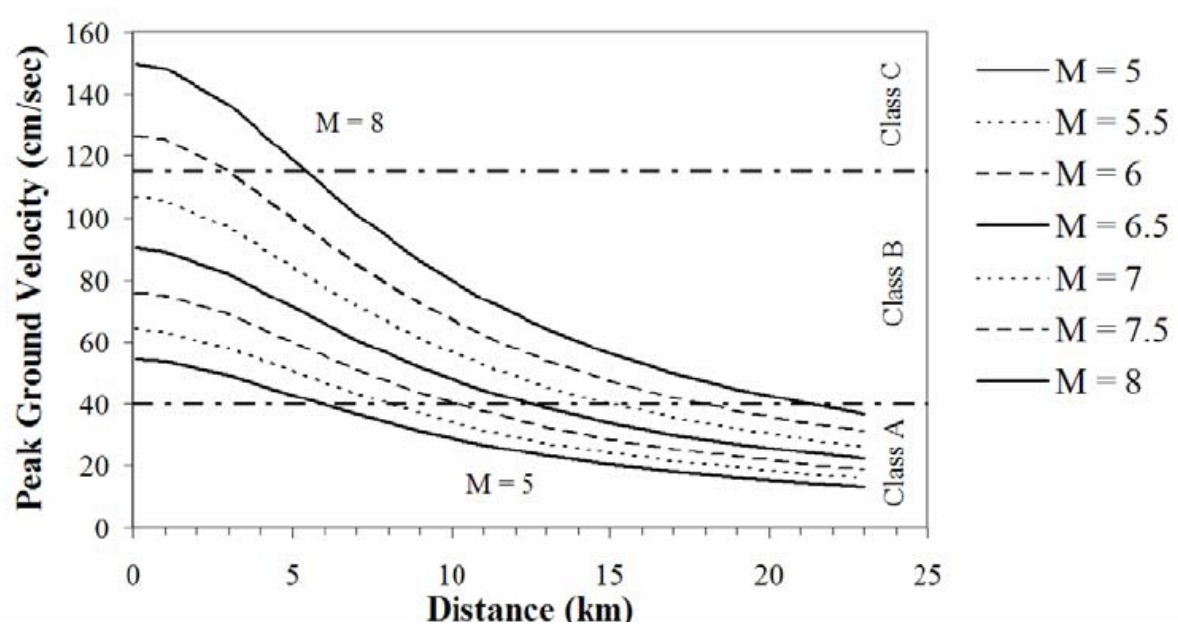

Figure 6 Comparison between PGV evaluated at free surface using Bray \& Rodriguez-Marek (2004) relation and damage level (Corigliano, 2007) 


\section{Earthquake magnitude}

Concerning with seismic damage of underground structures, several studies were carried out to correlate the damage level to earthquake magnitude, and the previous correlation is mainly focused on Richter magnitude. According to Dowding \& Rozen (1978), as shown in Figure 7, no damage occur for Richter magnitude less than 5, and rare heavy damage could be expected for Richter magnitude less than 7.Sharma \& Judd (1991) also contributed Richter magnitude to correlate the relevant damage degree to the earthquake intensity, and concluded that the cases of reported damage increased with increasing Richter magnitude, while more than half the damage reports were for events that exceeded magnitude 7.Corigliano(2007) correlated the damage cases to the moment magnitude and concluded that the level of damage increases as the earthquake magnitude increases, as shown in Figure 8.

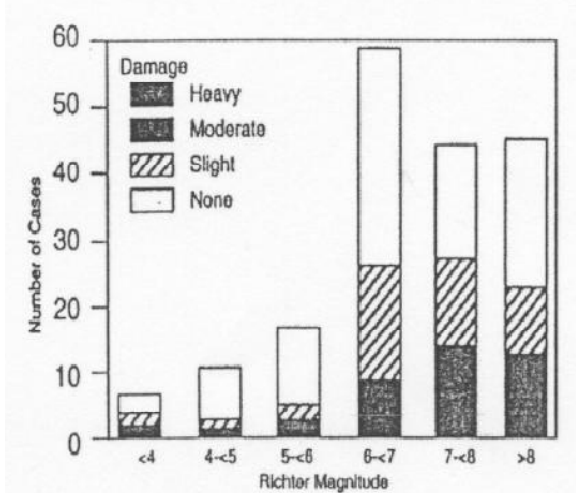

Figure 7 Correlation between Richer Magnitude and damage (Sharma \&Judd , 1991)

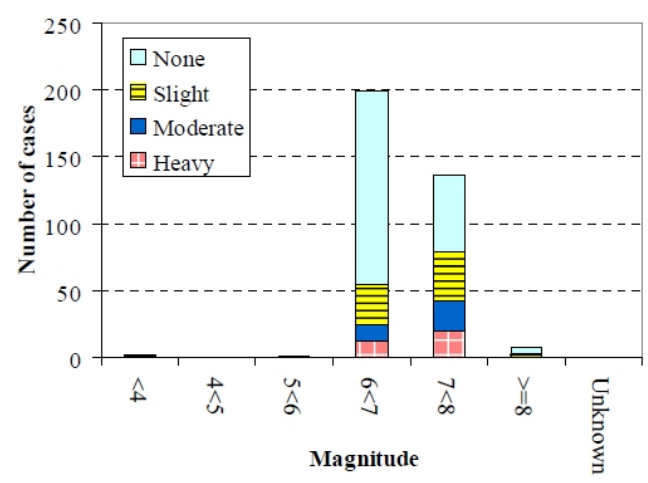

Figure 8 Effects of Moment Magnitude on the damage level (Corigliano, 2007)

For the assessment of the general damage tendency induced by earthquake, all the above magnitudes could provide satisfactory results. However, moment magnitude would be preferred to develop more accurate relations with other factors, since most underground damage would more likely occur for larger earthquakes.

\section{Duration}

According to Dowing \&Rozen(1978), duration of strong motion shaking during an earthquake is extremely important since it may cause fatigue failure and lead to large deformations, which is dependent on the total number of cycles induced by the ground shaking. Owen \& Scholl(1981) also indicted that duration of strong seismic motion appeared to be an important factor contributing to the severity of damage to underground structures. Due to a lack of relevant available damage cases, no correlation between duration and damage level could be presented here.

\section{Frequency}

Frequency content is significant for buried structures in as much as the response of the soil layers in which they are embedded is sensitive to frequency content, and it is important with respect to stability of underground openings(Carpenter \& Chung, 1986). Dowing \& Rozen(1978) suggested that the destructive frequencies may be expected mainly at small distances from a causative fault because higher frequency components attenuate more rapidly than the lower frequency components. The high frequency effect may also contribute to the local spalling of rock or concrete. Besides, 
frequencies most likely to damage sub-surface openings are significantly higher $(50-100 \mathrm{~Hz})$ than the frequencies $(2-10 \mathrm{~Hz})$ that cause damage to surface facilities (Pratt et, al, 1980).

\section{Conclusions}

Based on the above surveys, one may conclude that The damage level of underground structures could be well correlated to ground motion parameters such as PGA, PGV and magnitude. PGV is more preferred to characterize the earthquake effect compared with PGA. Damage level increases with the increase of earthquake magnitude. duration and frequency are also of great importance to affect the performance of an underground structure during seismic events

\section{Acknowledgements}

This work was financially supported by the National Natural Science Fund(51668002, 51568001), t he Jiangxi Provincial Natural Science Fund.(20161BAB216145, GJJ160562, GJJ150567) and the R esearch Start-up Fund of ECUT (DHBK2013203,DHBK2013202).

\section{References}

1. American Lifelines Alliance. (2001): Seismic fragility formulations for water systems. Part 1 - Guideline. ASCE-FEMA

2. Carpenter, D.W., Chung, D.C. (1986): Effects of earthquakes on underground facilities. NUREG/CR-4609 p. 152, Lawrence Livermore National Lab.

3. Corigliano, M. (2007): Seismic response of rock tunnels in near-fault conditions. Doctoral thesis, Politecnico di Torino.

4. Dowding, C.H., Rozen, A. (1978): Damage to rock tunnels from earthquake shaking. American Society of Civil Engineers. Journal of the Geotechnical Engineering Division. Vol. 104(2 Feb): p. 175-191.

5. Hashash, Y.M.A., Hook, J.J., Schmidt, B., Yao, J.I.C. (2001): Seismic design and analysis of underground structures. Tunnelling and Underground Space Technology, 16, 247-293.

6. Pratt, H.R., Stephenson, D.E., Zandt, G., Bouchon, M., Hustrulid, W.A. (1980): Earthquake damage to underground facilities. Rapid excavation and tunneling conference. Littleton, CO, USA, June 1980. Conf-800603-1, 48p. In Workshop on Seismic Performance of Underground Facilities, p. 43-74.

7. Bray, J.D., Rodriguez-Marek, A. (2004): Characterization of forward directivity ground motion in the near fault region. Soil Dynamic and Earthquake Engineering, 24, 815-828, 2004.

8. John, C.M., Zahrah, T.F. (1987): Aseismic design of underground structures. Tunnelling and Underground Space Technology, 2, (2).

9. Owen, G.N., Scholl, R.E. (1981): Earthquake engineering of large underground structures.Report no. FHWA/RD-80/195. Federal Highway Administration and National Science Foundation.

10. Power, M.S., Rosidi, D., Kaneshiro, J.Y. (1998): Seismic vulnerability of tunnels andunderground structures revisited. Proc of North American Tunnelling'98. Newport Beach, CA: Balkema, Rotterdam, The Netherlands, p. 243-250.

11. Kramer, S.L. (1996): Geotechnical earthquake engineering. Prentice Hall, Upper Saddle River, NJ. 
12. Sharma, S., Judd. (1991): Underground opening damage from earthquakes. Engineering Geology, vol. 30, pp. 263.276. 